\title{
ARTICLE
}

\section{Evaluation of retention and excretion function to members of the public for chronic intakes of radionuclides}

\author{
Shinji Hato ${ }^{\mathrm{a}, \mathrm{c}^{*}}$, Sakae Kinase ${ }^{\mathrm{b}, \mathrm{c}}$ and Masanori Kimura ${ }^{\mathrm{b}}$ \\ ${ }^{a}$ Visible Information Center, 440 Muramatsu Tokai-mura, Naka-gun, Ibaraki-ken, 319-1112, Japan; ${ }^{b} J a p a n$ Atomic Energy Agency, \\ 2-4 Shirakata, Tokai-mura, Naka-gun, Ibaraki-ken, 319-1195, Japan; ${ }^{C}$ Ibaraki University, 2-1-1 Bunkyo, Mito, Ibaraki-ken, \\ 310-8512, Japan
}

\begin{abstract}
The Fukushima Dai-ichi Nuclear Power Plant accident resulted in a release of radionuclides to the environment and a wide range of radioactive contamination. The national government and local governments implemented urgent protective actions to reduce internal exposure from ingestion of food and tap water or inhalation of radionuclides after the accident. There has been some concern in evaluating internal exposure due to chronic intakes. DSYS-Chronic code was developed to evaluate internal exposures due to chronic intakes since the International Commission of Radiation Protection (ICRP) has evaluated only the internal exposures due to acute intakes. It was found that there are intrinsically different burdens between acute and chronic intakes.
\end{abstract}

\section{Keywords: Fukushima; nuclear accident; chronic intakes; retention; excretion}

\section{Introduction}

The Fukushima Dai-ichi Nuclear Power Plant accident occurred on March 11, 2011 and resulted in a release of radionuclides to the environment and a wide range of radioactive contamination. Members of the public might have ingested contaminated food and tap water or inhaled radionuclides in the atmosphere until the national government and local governments implemented urgent protective actions after the accident. Hence, there has been some concern in evaluating internal exposure from chronic intakes.

However, the International Commission of Radiation Protection (ICRP) has evaluated only the internal exposures due to acute intakes, except equilibrium values for continuous chronic inhalation at a rate of $1 \mathrm{~Bq}$ $\mathrm{y}^{-1}$ for occupational works in the ICRP Publication 78 [1]. It is important to evaluate internal exposure due to chronic intakes for the members of the public in the Fukushima accident with contaminated food and tap water. In recent years, the ICRP mentions that there is intrinsically different burden between acute and chronic intakes as the same total intake [2].

The Japan Atomic Energy Agency (JAEA) has developed DSYS that evaluates the internal doses for tissue or organ based on dosimetric and biokinetic models of the ICRP [3-4]. The DSYS was enhanced to evaluate internal exposures not only for acute intakes, but also for chronic intakes, and named as
DSYS-Chronic. The objective of the present study is to provide retention and excretion function for chronic intakes.

\section{Computation for acute and chronic intakes}

\subsection{Acute intakes}

The retention activity of radionuclides is expressed by compartmental model consisted of organ and tissues and is described by first-order kinetics equations as Eq. (1).

$$
\frac{\mathrm{d} \mathbf{q}(\mathrm{t})}{\mathrm{dt}}=\mathbf{A}(\mathrm{t}) \cdot \mathbf{q}(\mathrm{t}), \mathbf{q}(\mathrm{t}=0)=\mathbf{q}_{0}
$$

where

$\mathbf{q}(\mathrm{t})=$ the vector of the retention activity of radionuclides in each compartment at time $t$ after intake $[\mathrm{Bq}]$

$\mathbf{A}(\mathrm{t})=$ the matrix of the age dependent transfer coefficients between compartments and decay constant of radionuclides [1/day]

$\mathbf{q}_{0}=$ the vector of initial values $[\mathrm{Bq}]$

The acute intake is a single intake of radionuclides at $\mathrm{t}=0$ as Eq. (1).

\subsection{Chronic intakes}

The equations of the chronic intakes are added to Eq. (1) with external feed as Eq. (2).

*Corresponding author. Email: hato@ vic.co.jp 


$$
\frac{\mathrm{d} \mathbf{q}(\mathrm{t})}{\mathrm{dt}}=\mathbf{A}(\mathrm{t}) \cdot \mathbf{q}(\mathrm{t})+\dot{\mathbf{I}}(\mathrm{t}), \mathbf{q}(\mathrm{t}=0)=\mathbf{0}
$$

where

$\dot{I}(t)=$ the vector of external feed for chronic intakes [Bq/day]

The chronic intakes are continuous intakes of radionuclides during some periods.

The DSYS-Chronic computes Eq. (1) and (2) by using numerical solver of ordinary differential equations that are stiff equations.

\section{Material and methods}

\subsection{DSYS-Chronic code}

The DSYS-Chronic code, which was developed at the Japan Atomic Energy Agency, can treat internal dosimetry using the ICRP's respiratory tract, GI-tract, tissue dosimetry, biokinetic and bioassay models for ICRP Publication 71 [5]. Retention and Excretion from acute and chronic intakes were evaluated by using this code.

\subsection{Difference between acute and chronic intakes}

The ICRP mentions that the evolution of the whole-body activity associated with an acute intake of $1000 \mathrm{~Bq}$ of ${ }^{137} \mathrm{Cs}$ and with a daily chronic intake of $1 \mathrm{~Bq}$ of ${ }^{137} \mathrm{Cs}$ over 1000 day is significantly different even though the same total intake. In addition, The ICRP indicates intrinsically different burden between acute and chronic intake [2]. These difference were confirmed by using the DSYS-Chronic.

\subsection{Measurement data in the Fukushima accident}

Temporal changes in the concentration of iodine 131 in tap water were measured after the Fukushima Dai-ichi Nuclear Power Plant accident [6]. Figure 1 shows the concentration of iodine 131 in tap water at a local area of Fukushima. The concentration of iodine 131 in tap water was 965 [Bq/kg] on March 20, 2011 and decreased gradually till reaching below a detection limit after April 11, 2011.

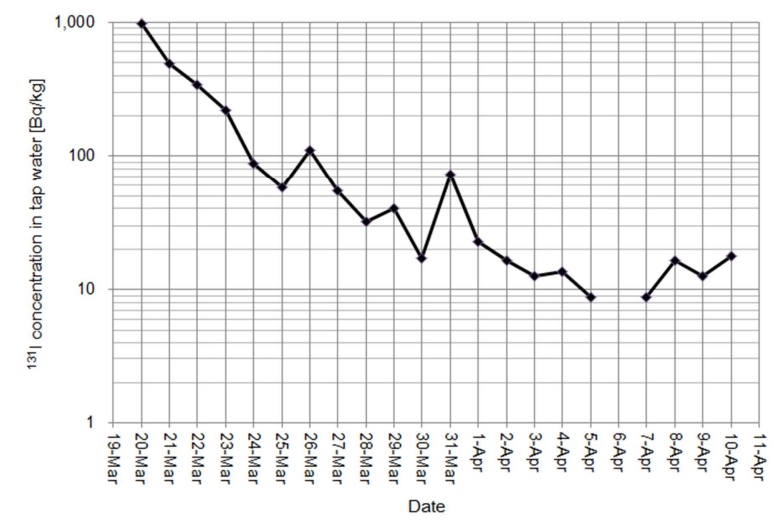

Figure 1. Concentration of iodine 131 in tap water at Fukushima.
Figure 2 depicts daily intake rate of iodine 131 from for 1-year-old children, assuming tap water consumption 1.4 [1/day] [7]. The rate assumes constant daily intake based on the concentration of iodine 131 in tap water of the Figure 1. The retention and excretion were evaluated by the DSYS-Chronic with daily intake rate in Figure 2 as the external feed of Eq. (2).

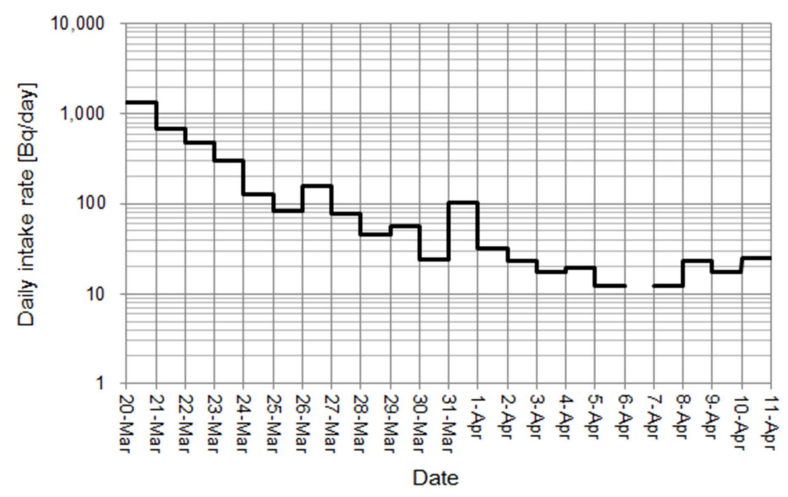

Figure 2. Daily intake rate of tap water contaminated by iodine 131 for 1-year-old children.

\section{Results and discussion}

\subsection{Comparison between acute and chronic intakes}

Figure 3 presents the whole body activity due to ingestion for 1-year-old children associated with acute intake of $365 \mathrm{~Bq}$ of ${ }^{137} \mathrm{Cs}$ and with a daily intake of 1 $\mathrm{Bq}$ of ${ }^{137} \mathrm{Cs}$ over 365 days. For the same total intake, the resulting whole body activity at the end of the period is significantly different. These time integrals are $6.9 \times 10^{3}[\mathrm{~Bq}$ day $]$ for acute intake and $7.2 \times 10^{3}[\mathrm{~Bq}$ day] for chronic intake. These illustrate the intrinsically different burden between acute intake and chronic intake.

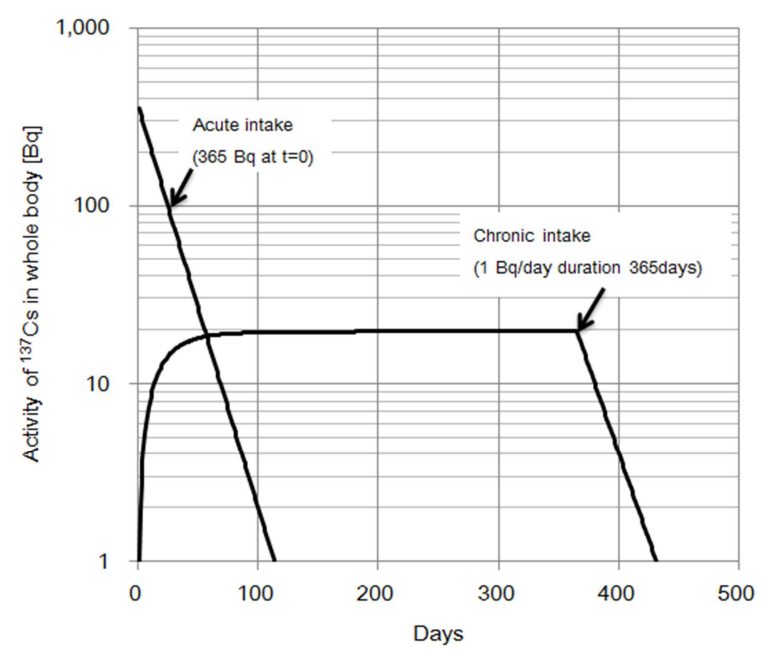

Figure 3. Activity in whole body due to ingestion of ${ }^{137} \mathrm{Cs}$ for 1-year-old children. 


\subsection{Evaluation based on measurement data}

Retention and excretion for 1-year-old children due to chronic intakes of iodine 131 through tap water are shown in Figure 4. The excretion is larger in urine than in faeces. The retention in whole body and thyroid is lower than $1 \mathrm{~Bq}$ at about 60th day. The retention in thyroid is the main contributor to the retention in whole body. Hence, it is important to block uptake to thyroid promptly in emergency exposure situation resulting in the release of radioactive iodine.

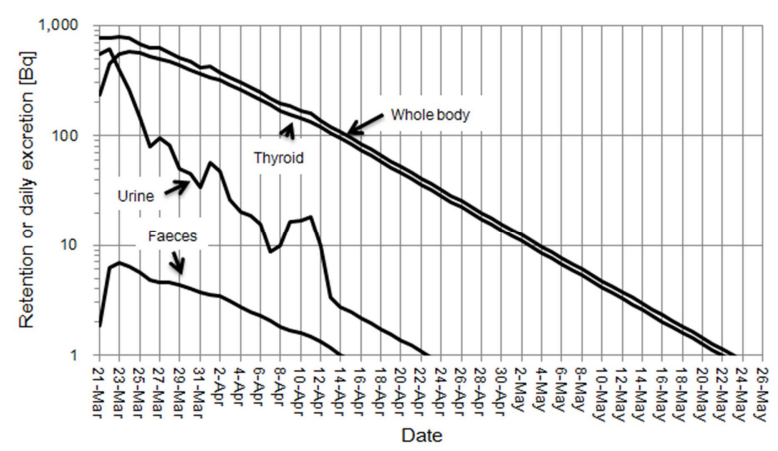

Figure 4. Retention and daily excretion of 1-year-old children for chronic intake of tap water contaminated by iodine 131 .

\section{Conclusions}

The features of acute and chronic intakes were studied. Consequently, it was found that these intakes are significantly different retention and introduce intrinsically different burden.

Retention and excretion for 1-year-old children due to chronic intakes of iodine 131 through tap water were studied with measurement data after the Fukushima
Dai-ichi nuclear power plant accident. The retention in thyroid decreased to about $1 \mathrm{~Bq}$ at 60th day.

\section{References}

[1] ICRP, Individual Monitoring for Internal Exposure of Workers, ICRP Publication 78, Ann. ICRP 27 (3-4) (1997).

[2] ICRP, Application of the Commission's Recommendations to the Protection of People Living in Long-term Contaminated Areas after a Nuclear Accident or a Radiation Emergency, ICRP Publication 111, Ann. ICRP 39 (3) (2009).

[3] S. Hato, M. Terakado, K. Tomita and T. Homma, User's Manual of DSYS-GUI: The Calculation System of Internal Dose Coefficients, JAEA-Data/Code 2008-031, Japan Atomic Energy Agency, (2009). [in Japanese]

[4] S. Hato and T. Homma, Internal Dose Coefficients for Off-site Radiological Consequence Analysis of Nuclear Reactor Accidents, JAERI-Data/Code 2005-006, Japan Atomic Energy Research Institute, (2005). [in Japanese]

[5] ICRP, Age-dependent Doses to Members of the Public from Intake of Radionuclides - Part 4 Inhalation Doses Coefficients, ICRP Publication 71, Ann. ICRP 25 (3-4) (1995).

[6] Ministry of Health Labour and Welfare, Information about the Great East Japan Earthquake, Online, Available: http://www.mhlw.go.jp/English/topics/2011eq/ind in.html (2011, April 17).

[7] Ministry of Education, Culture, Sports, Science and Technology-Japan, Technical Guideline of Radiation Council to Assessment of External and Internal Exposure (1999). [in Japanese] 